\title{
in the classroom
}

\section{Doing your own thing}

\author{
The spirit of collaboration in a one-room schoolhouse in rural Scotland served as a model for being creative in \\ science, as Fraser Stoddart explains, recounting his journey to Stockholm.
}

A $s$ an only child growing up in the wake of World War II on a tenant farm nestling on the edge of the Southern Uplands of Scotland, I had to find ways to amuse myself. Solving jigsaw puzzles acted as an immense source of satisfaction for a while, even though I was not in it for the long haul. I tended to want to feast my eyes on a puzzle completed speedily and move onto the next one. Quick fixes and finished jobs were essential outcomes for the impatience residing inside me.

With the onset of my formal education at a small village school, I was introduced to a style of learning where the more mature and able members of the one and only class played their part in helping the younger and less gifted pupils. The satisfaction I draw from helping others was thus instilled in me from a very early age. This human trait spilled over into my high school education. The biggest prize I collected on leaving school was not for outstanding academic achievement, but rather for service to the school. During my subsequent academic career, I focused on putting the well-being of my students before my own aspirations and ambitions. This disposition has meant that much of the success I have chalked up in my professional life is owed to the close to 500 graduate students and postdoctoral scholars I have mentored.

Living the daily routine for a quarter of a century on a mixed arable farm in the good times and the bad, surrounded by German prisoners of war, Irish labourers and some very strong and single-minded women, gave me an early appreciation of the virtues that flow from diversity. Such diversity is practiced on the grandest of scales in a research group whose members are drawn from different countries and cultures. It is one reason why I am exercised by the current drive towards isolationism and protectionism in some countries in the Western world. Building walls to create comfort zones for small groups of people, be it in science or anything else, is a retrograde step of the first order.

Another lesson I learnt on the farm is the necessity of keeping up with the times. Nothing is gained, save a bit of nostalgia for what it is worth, and much is lost from living in the past. The 'good old days' are an illusion. Just as the twentieth century agricultural revolution obliged farmers to embrace new practices and continually purchase the latest implements, so it has been

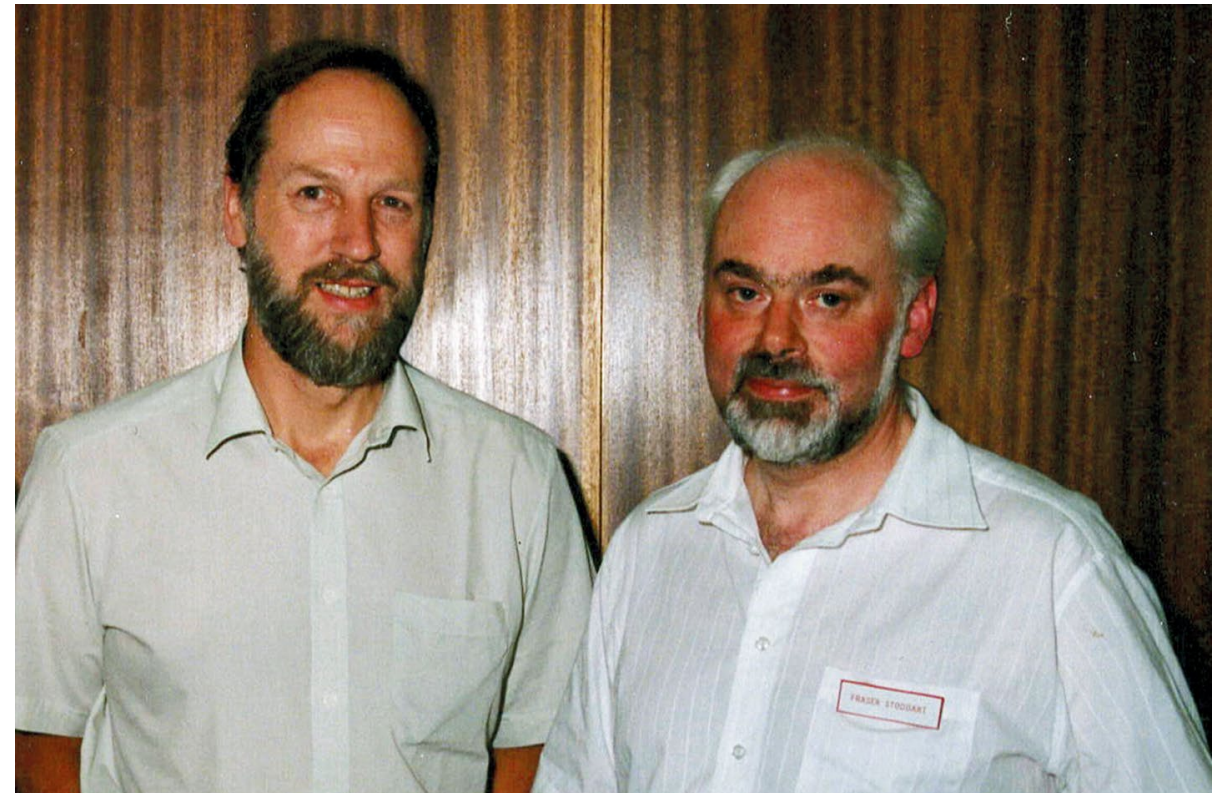

Fraser Stoddart with David Williams in 1991. Credit: Photo taken by the late Dr Norma Stoddart

my experience in the running of research laboratories these past 50 years. Access to state-of-the-art equipment, in some instances made to sing and dance by highly trained experts, is an essential prerequisite in the execution of cutting-edge research.

Oftentimes, by far the best outcomes in science are the result of collaborations. This dynamic has served my research group well at different stages in its history. My collaboration with David Williams at Imperial College London between 1974 and 1997 led to the introduction of a new strong bond - the mechanical bond - into chemistry. It would not have happened without the 1,000 or thereabouts solid-state structures originating from the Williams X-ray crystallography laboratory. This collaboration was as close as they come to being ideal.

While it takes all that I have mentioned and more to achieve something that is impactful in contemporary science, to be singled out as a scientist who leaves their mark on science and ultimately technologies, you need to become recognized widely as having done your own thing. This means that you make a conscious decision to summon up enough courage to tackle a big problem for which no one has provided a satisfactory scientific answer. It follows that you have to make a real and determined effort to forsake the beaten track. It requires both curiosity and zeal. As Mihaly Csikszentmihalyi points out in his book Creativity: Flow and Psychology of Discovery and Invention, "the first requires openness to outside stimuli: the second demands inner focus. The first is playful, passionate and fun-oriented: the second is serious, competitive and achievement-directed. The first is about concepts and ideas: the second is about their implementation. Both are required for creativity to be actualized." It was by following these two pathways of curiosity and zeal, beginning at the Imperial Chemical Industries Corporate Laboratory in Runcorn, England, and working hand-in-hand with David Williams, that I ended up introducing mechanical bonds into molecules, which then led to building molecular machines. The journey to Stockholm was a long one, and it was often uphill, but it worked out for me and my research group in the end. It can work out for you as well, provided you set your mind firmly on doing your own thing.

\section{Fraser Stoddart}

Department of Chemistry, Northwestern University, Evanston, IL, USA.

e-mail: stoddart@northwestern.edu

Published online: 6 March 2018

https://doi.org/10.1038/s41565-018-0090-6 